\title{
Fatty Acid Profile of Fat of Grass Carp, Bighead Carp, Siberian Sturgeon, and Wels Catfish
}

\author{
Renata Pyz-Lukasik ${ }^{1}$ and Danuta Kowalczyk-Pecka ${ }^{2}$ \\ ${ }^{1}$ Department of Food Hygiene of Animal Origin, Faculty of Veterinary Medicine, University of Life Sciences in Lublin, \\ Ul. Akademicka 12, 20-950 Lublin, Poland \\ ${ }^{2}$ Department of Zoology, Animal Ecology and Wildlife Management, University of Life Sciences in Lublin, \\ Ul. Akademicka 13, 20-033 Lublin, Poland \\ Correspondence should be addressed to Renata Pyz-Łukasik; renata.pyz@up.lublin.pl
}

Received 13 October 2017; Revised 18 November 2017; Accepted 27 November 2017; Published 25 December 2017

Academic Editor: Domenico Montesano

Copyright (C) 2017 Renata Pyz-Łukasik and Danuta Kowalczyk-Pecka. This is an open access article distributed under the Creative Commons Attribution License, which permits unrestricted use, distribution, and reproduction in any medium, provided the original work is properly cited.

\begin{abstract}
The objective of this study was to determine fish species differences in fatty acid profile of the fat of farmed grass carp, bighead carp, Siberian sturgeon, and wels catfish so as to compare the consumer health benefits they provide. Fatty acid composition range was as follows: saturated fatty acids (SFA), $16.32 \%-32.96 \%$; monounsaturated fatty acids (MUFA), $41.84 \%-55.31 \%$; and polyunsaturated fatty acids (PUFA), $13.4 \%-26.31 \%$. The total content of eicosapentaenoic acid (EPA) and docosahexaenoic acid (DHA) in $100 \mathrm{~g}$ of muscle tissue of the fish examined in the current study was $62.61 \mathrm{mg}$ for grass carp, $150.51 \mathrm{mg}$ for wels catfish, $488.67 \mathrm{mg}$ for bighead carp, and $619.06 \mathrm{mg}$ for Siberian sturgeon. The ratios of n-6/n-3 (0.44-1.72) and PUFA/SFA (0.45-1.61) in the fat of the fish analyzed were beneficial.
\end{abstract}

\section{Introduction}

Higher nutritive value of fish is well documented in the studies of many authors [1-7]. It comes mainly from easily digestible protein and fat it contains [8]. In recent years, increasing attention has been focused on the significance of fatty acids in human nutrition. Fish fat is characterized by an advantageous composition of fatty acids. The assessment of fatty acid profile includes the level of saturated fatty acids (SFA), monounsaturated fatty acids (MUFA), polyunsaturated fatty acids (PUFA), and n-3 and n-6 family as well as the ratio of n- 6 to n-3 and PUFA to SFA. Furthermore, the amount of eicosapentaenoic acid (EPA) and docosahexaenoic acid (DHA) from the n-3 family and arachidonic acid (AA) from the $n-6$ family is of great importance. These acids are essential for normal growth and development of organism as well as health promotion and disease prevention [9-15].

A number of authors evaluated fatty acid profile of marine or farmed fish along with consumer health benefits provided by dietary inclusion of the studied fish $[8,16-22]$. However, the data on nutritive value of fat of the selected fish species from the fishing farms in eastern Poland are limited.

The objective of the present study was determination of fish species variation in fatty acid profile of fat in important farmed food fish such as grass carp (Ctenopharyngodon idella), bighead carp (Aristichthys nobilis), Siberian sturgeon (Acipenser baerii), and wels catfish (Silurus glanis) and comparison of their health-promoting benefits for consumers.

\section{Materials and Methods}

2.1. Samples and Analysis. Research material included muscle tissue of grass carp (Ctenopharyngodon idella) $(n=6)$, bighead carp (Aristichthys nobilis) $(n=6)$, Siberian sturgeon (Acipenser baerii) $(n=6)$, and wels catfish (Silurus glanis) $(n=6)$. The aforementioned fish species were caught at the fish farms located in eastern Poland. Grass carp and bighead carp are herbivorous fish, whereas Siberian sturgeon and wels catfish are predatory fish. The fish ate natural alimentation which was in pond and did not receive any industrial feed. 
After fish harvesting and killing, the body weight and length of each fish were measured. Within an hour, the fish were transported at $0^{\circ} \mathrm{C}-4^{\circ} \mathrm{C}$ to the laboratory, where they were gutted and filleted. A laboratory sample consisted of a pair of fillets from each fish, minced twice and then homogenized.

Following lyophilization of the tissues, lipids were extracted with a Soxhlet extractor (VELP SCIENTIFICA SER 148 Solvent Extractor) [23]. To obtain fatty acids for analysis, $100 \mathrm{mg}$ of fat was collected. Fatty acid esters were obtained according to international standards [24, 25]. The samples obtained were analyzed using a Varian 3800 gas chromatograph with a FID detector and a CP-Wax 52CB WCOT Fused Silica capillary column, with length of $60 \mathrm{~m}$ and an inner diameter of $0.25 \mathrm{~mm}$. The initial temperature for the analysis was $120^{\circ} \mathrm{C}$ for 5 minutes and the final temperature was $210^{\circ} \mathrm{C}$. The injector temperature was $260^{\circ} \mathrm{C}$ and the detector temperature was $260^{\circ} \mathrm{C}$. The hydrogen flow rate was $30 \mathrm{ml} / \mathrm{min}$, air $300 \mathrm{ml} / \mathrm{min}$, and helium $1.4 \mathrm{ml} / \mathrm{min}$. The volume of the injected sample was $1 \mu \mathrm{l}$. The results for the percentage content of fatty acids in the sample were obtained using Star GC Workstation Version 6.30.

The content of fatty acids expressed in $\mathrm{mg} / 100 \mathrm{~g}$ muscle tissue was calculated using a conversion factor of 0.956 and the total lipid content of fish muscle tissue [26].

2.2. Statistical Analysis. The results presented as means \pm SD were submitted to analysis of variance (MANOVA) at 0.05 significance level, using Statistica 10. The mean values were compared by Tukey's test.

\section{Results and Discussion}

The mean body weight and length were $2.47 \pm 0.22 \mathrm{~kg}$ and $58.67 \pm 1.75 \mathrm{~cm}$ for grass carp, $2.64 \pm 0.19 \mathrm{~kg}$ and $50.58 \pm$ $0.92 \mathrm{~cm}$ for bighead carp, $2.17 \pm 0.82 \mathrm{~kg}$ and $79.83 \pm 9.02 \mathrm{~cm}$ for Siberian sturgeon, and $2.71 \pm 0.15 \mathrm{~kg}$ and $74.17 \pm 1.17 \mathrm{~cm}$ for wels catfish.

As for the fish analyzed in this study, a fat content (\%) in the muscle tissue was $10.84 \pm 2.98$ for Siberian sturgeon, 9.42 \pm 2.21 for bighead carp, $3.33 \pm 1.83$ for wels catfish, and 3.07 \pm 0.63 for grass carp. According to the Polish Standard [27], Siberian sturgeon and bighead carp were fat fish, while wels catfish and grass carp were medium fat fish.

Fatty acid profiles of fat of grass carp, bighead carp, Siberian sturgeon, and wels catfish are given in Table 1 . The total saturated fatty acids (SFA) ranged from $16.32 \%$ up to $32.96 \%$. Grass carp and bighead carp had significantly more saturated fatty acids as compared to Siberian sturgeon and wels catfish. Saturated fatty acids levels reported by other authors in the same fish species were different from those obtained in the present research. Ljubojević et al. [28] indicated a higher SFA content in bighead carp $(32.82 \%)$ and wels catfish $(30.22 \%)$ but lower in grass carp $(28.72 \%)$. Badiani et al. [29] showed a higher SFA level in sturgeon (25.99\%). Four fish species discussed in this study contained less SFA compared to other freshwater fish species like pike, zander, bream, tilapia, and pangasius, whose SFA level was between $36.28 \%$ and $42.18 \%$ [22, 30]. Palmitic acid (C16:0) was the dominant SFA in the analyzed fish, from $10.50 \%$ in wels catfish up to $24.66 \%$ in grass carp, contributing $64.34 \%-78.61 \%$ of the total saturated fatty acid (SFA). Palmitic acid was also found as the major SFA in the lipids of many freshwater fish species with percentage $16.83 \%-29.19 \%$ $[22,30]$. Stearic (C18:0) and myristic acid (C14:0) followed palmitic acid with regard to the quantity in the saturated fatty acid group determined in the fat of grass carp, bighead carp, wels catfish, and Siberian sturgeon. The content of these acids was as follows: $1.59 \%-5.48 \%$ and $1.57 \%-2.50 \%$, respectively. Alike, stearic acid and myristic acid were the next highest in the saturated fatty acid group of the fish from the Vistula Lagoon such as bream, eel, roach, perch, and pike perch ranging within $3.62 \%-6.02 \%$ and $1.55 \%-4.03 \%$, respectively [8]. Monounsaturated fatty acids (MUFA) were found most abundant in the fat of the studied fish species; their level in wels catfish, Siberian sturgeon, and bighead carp was comparable $(54.08 \%-55.31 \%)$ but significantly higher than in grass carp (41.84\%). The aforementioned fish species showed the greatest amount of oleic acid (C18:1 n-9) within the range $29.35 \%-47.71 \%$ making up $69.12 \%-88.20 \%$ of the total monounsaturated fatty acids (MUFA). Palmitoleic acid (C16:1 n-9) varying within $2.22 \%-10.90 \%$ and vaccenic acid (C18:1 n-7) $2.74 \%-4.42 \%$ followed in order of the most abundant acids. The quantity of other fatty acids identified in this group was below 1\%. Ljubojević et al. [28] highlighted a higher content of monounsaturated fatty acids in grass carp (50.6\%) but lower in bighead carp (33.48\%) and wels catfish (41.43\%) as compared to the levels established in the same fish species in the present research. Badiani et al. [29] reported that MUFA content in sturgeon maintained level between $43.08 \%$ and $51.82 \%$ and the value close to the upper limit was determined in the present studies on this fish species. Like this research, oleic acid (18:1 n-9) in these fish species had the highest level in the group of monounsaturated fatty acids ranging between $24.00 \%$ and $38.83 \%$ [28]. In other freshwater fish species such as zander, pike, bream, and carp, oleic acid (18:1 n-9) also prevailed ranging from $16.01 \%$ up to $32.63 \%$, whereas a content of monounsaturated fatty acids was lower (27.46\%-48.57\%) than that obtained in the present research in bighead carp, Siberian sturgeon, and wels catfish [22]. A level of polyunsaturated fatty acids (PUFA) in the fat of Siberian sturgeon, grass carp, and wels catfish was significantly higher $(24.24 \%-26.31 \%)$ compared to bighead carp (13.4\%). As for grass carp, Siberian sturgeon, and wels catfish, linoleic acid (C18:2 n-6) was most abundant, at the level of 9.56\%-15.15\% whereas linolenic acid (C18:3 n-3) dominated in bighead carp-3.52\%. The PUFA n-6 content was the highest in wels catfish $(16.63 \%)$ comparable to Siberian sturgeon and grass carp $(14.00 \%$ and $13.64 \%$, resp.), while the lowest content was in bighead carp (4.11\%). The PUFA n-3 level was similar in four fish species varying between $9.29 \%$ and $10.94 \%$. The other studies $[28,29]$ indicated a lower PUFA n-6 content in sturgeon (4.31\%) and wels catfish (11.18\%), while being higher in bighead carp (9.31\%). Regarding grass carp, it was comparable (13.63\%) to those obtained for these fish species in the present research. In these studies, PUFA $\mathrm{n}-3$ content was lower in grass carp (7.46\%) and higher in bighead carp, sturgeon, and wels catfish $(24.54 \%, 18.09 \%$, 
TABLE 1: Fatty acid composition (\%) of the fat extracted from analyzed fish (mean value \pm SD).

\begin{tabular}{|c|c|c|c|c|}
\hline Fatty acid & Grass carp & Bighead carp & Siberian sturgeon & Wels catfish \\
\hline $\mathrm{C} 12: 0$ & $0.04 \pm 0.01$ & $0.10 \pm 0.04$ & $0.01 \pm 0.01$ & $0.03 \pm 0.01$ \\
\hline $\mathrm{C} 13: 0$ & $0.02 \pm 0.01$ & $0.07 \pm 0.02$ & ND & $0.01 \pm 0.00$ \\
\hline $\mathrm{C} 14: 0$ & $1.76 \pm 0.36$ & $2.50 \pm 0.25$ & $1.79 \pm 0.10$ & $1.57 \pm 0.14$ \\
\hline $\mathrm{C} 15: 0$ & $0.28 \pm 0.08$ & $0.64 \pm 0.06$ & $0.20 \pm 0.01$ & $0.18 \pm 0.01$ \\
\hline $\mathrm{C} 16: 0$ & $24.66 \pm 3.00$ & $21.15 \pm 1.69$ & $14.44 \pm 0.49$ & $10.50 \pm 0.68$ \\
\hline $\mathrm{C} 17: 0$ & $0.42 \pm 0.18$ & $0.63 \pm 0.09$ & $0.14 \pm 0.03$ & $0.18 \pm 0.05$ \\
\hline $\mathrm{C} 18: 0$ & $5.48 \pm 1.25$ & $4.69 \pm 0.49$ & $1.59 \pm 0.22$ & $3.22 \pm 0.31$ \\
\hline $\mathrm{C} 20: 0$ & $0.15 \pm 0.03$ & $0.20 \pm 0.03$ & $0.16 \pm 0.03$ & $0.45 \pm 0.05$ \\
\hline $\mathrm{C} 22: 0$ & $0.13 \pm 0.07$ & $0.05 \pm 0.02$ & $0.04 \pm 0.02$ & $0.16 \pm 0.02$ \\
\hline $\mathrm{C} 24: 0$ & $0.02 \pm 0.01$ & $0.01 \pm 0.00$ & $\mathrm{ND}$ & $0.02 \pm 0.01$ \\
\hline$\sum S F A$ & $32.96^{a}$ & $30.04^{a}$ & 18.370 & $16.32^{b}$ \\
\hline $\mathrm{C} 14: 1$ & $0.07 \pm 0.03$ & $0.08 \pm 0.04$ & $0.02 \pm 0.00$ & $0.02 \pm 0.01$ \\
\hline $\mathrm{C} 15: 1$ & $0.09 \pm 0.05$ & $0.03 \pm 0.01$ & $0.01 \pm 0.00$ & $0.03 \pm 0.01$ \\
\hline $\mathrm{C} 16: \ln -7$ & $0.49 \pm 0.12$ & $0.61 \pm 0.26$ & $0.26 \pm 0.16$ & $0.29 \pm 0.14$ \\
\hline C16:1n-9 & $8.66 \pm 3.43$ & $10.90 \pm 0.75$ & $3.44 \pm 0.36$ & $2.22 \pm 0.45$ \\
\hline C17:1 & $0.34 \pm 0.08$ & $0.92 \pm 0.09$ & $0.15 \pm 0.06$ & $0.1 \pm 0.01$ \\
\hline $\mathrm{C} 18: \ln -7$ & $2.74 \pm 0.43$ & $4.42 \pm 0.39$ & $3.08 \pm 0.20$ & $3.60 \pm 0.32$ \\
\hline C18:1 n-9 & $29.35 \pm 5.21$ & $38.23 \pm 2.03$ & $47.71 \pm 0.65$ & $47.70 \pm 2.52$ \\
\hline C20:1n-7 & $0.10 \pm 0.05$ & $0.12 \pm 0.11$ & $0.05 \pm 0.04$ & $0.12 \pm 0.01$ \\
\hline$\sum M U F A$ & $41.84^{a}$ & $55.31^{b}$ & $54.72^{b}$ & $54.08^{b}$ \\
\hline$C 18: 2 n-6$ & $9.56 \pm 0.98$ & $2.14 \pm 0.40$ & $12.41 \pm 0.63$ & $15.15 \pm 0.95$ \\
\hline$C 20: 2 n-6$ & $0.40 \pm 0.18$ & $0.10 \pm 0.04$ & $0.29 \pm 0.23$ & $0.45 \pm 0.11$ \\
\hline$C 18: 3 n-3$ & $7.91 \pm 3.60$ & $3.52 \pm 0.77$ & $3.36 \pm 0.32$ & $4.19 \pm 0.48$ \\
\hline$C 18: 3 n-6$ & $0.20 \pm 0.07$ & $0.24 \pm 0.06$ & $0.68 \pm 0.06$ & $0.21 \pm 0.03$ \\
\hline$C 20: 3 n-6$ & $0.75 \pm 0.27$ & $0.29 \pm 0.12$ & $0.15 \pm 0.10$ & $0.42 \pm 0.06$ \\
\hline$C 20: 4 n-6$ & $2.72 \pm 0.69$ & $1.34 \pm 0.40$ & $0.48 \pm 0.03$ & $0.4 \pm 0.10$ \\
\hline$C 20: 5 n-3$ & $1.10 \pm 0.50$ & $2.92 \pm 0.80$ & $2.38 \pm 0.25$ & $1.63 \pm 0.42$ \\
\hline$C 22: 5 n-3$ & $0.86 \pm 0.30$ & $0.56 \pm 0.24$ & $0.79 \pm 0.13$ & $0.85 \pm 0.24$ \\
\hline $\mathrm{C} 22: 6 n-3$ & $1.08 \pm 0.35$ & $2.29 \pm 0.66$ & $3.7 \pm 0.37$ & $3.01 \pm 0.81$ \\
\hline$\sum P U F A$ & $24.62^{a}$ & $13.4^{b}$ & $24.24^{a}$ & $26.31^{a}$ \\
\hline$\sum n-6$ & $13.64^{a}$ & $4.11^{b}$ & $14.00^{a}$ & $16.63^{c}$ \\
\hline$\sum n-3$ & $10.94^{a}$ & $9.29^{a}$ & $10.23^{a}$ & $9.68^{a}$ \\
\hline$n-6 / n-3$ & 1.24 & 0.44 & 1.37 & 1.72 \\
\hline PUFA/SFA & 0.75 & 0.45 & 1.32 & 1.61 \\
\hline
\end{tabular}

ND: not detected. Means in the same row with different superscript letters were significantly different, $p<0.05$.

and $17.21 \%$, resp.) $[28,29]$. In other freshwater fish species, the PUFA n-6 and PUFA n-3 level was differentiated and ranged within $8.46 \%-16.32 \%$ and $5.01 \%-24.85 \%$, respectively $[22,30]$. The PUFA n- 6 and n-3 values obtained in the present studies on four fish species were found within these ranges.

The ratio of PUFA n- 6 to n-3 and PUFA to SFA is of great importance for good health. Nutritionists emphasize the significance of maintaining a low $n-6$ to $n-3$ ratio in diets to prevent arteriosclerosis [8]. Values higher than the maximum are harmful to health and may contribute to cardiovascular diseases development [31]. The UK Department of Health recommends the maximum n-6 to $n-3$ ratio of 4.0 [32]. The ratio n-6 to n-3 in the fish examined in the current study was 0.44 for bighead carp, 1.24 for grass carp, 1.37 for sturgeon, and 1.72 for wels catfish and, thus, it did not exceed the recommended maximum dietary ratio of 4.0 [32]. The reports available in the literature present the ratio of PUFA n-6 to $\mathrm{n}-3$ in freshwater fish within the range of $0.21-2.78[17,28]$. Another important factor in the prevention of cardiovascular disease is the ratio of PUFA to SFA [8]. A minimum value of PUFA to SFA ratio recommended is 0.45 [32], whereas these ratios in the fish examined were equal to or higher than the recommended minimum value of 0.45 [32], that is, 0.45 for bighead carp, 0.75 for grass carp, 1.32 for sturgeon, and 1.61 for wels catfish. Ljubojević et al. [28] and Özogul et al. [17] reported the PUFA to SFA ratio for freshwater fish within the range $0.66-1.56$. The nutritive value of fish depends on the content of fatty acids that are beneficial to health [8]. The highest EPA level (eicosapentaenoic acid) was noted in the fat of bighead carp $(2.92 \%)$ followed by Siberian sturgeon $(2.38 \%)$, wels catfish (1.63\%), and grass carp (1.10\%). A DHA level (docosahexaenoic acid) was close to 
TABLE 2: Fatty acid content (mg/100 g) in the muscle tissue analyzed fish (mean value $\pm S D$ ).

\begin{tabular}{lcccc}
\hline Fatty acids & Grass carp & Bighead carp & Siberian sturgeon & Wels catfish \\
\hline SFA & $957.65 \pm 177.49$ & $2668.58 \pm 475.65$ & $1899.40 \pm 478.74$ & $512.12 \pm 267.45$ \\
MUFA & $1267.43 \pm 397.33$ & $5099.14 \pm 1216.44$ & $5923.41 \pm 1589.00$ & $1818.23 \pm 967.92$ \\
PUFA & $711.20 \pm 179.92$ & $1243.29 \pm 467.41$ & $2514.57 \pm 694.70$ & $849.91 \pm 514.22$ \\
n-3 & $316.48 \pm 129.40$ & $865.73 \pm 339.10$ & $1052.46 \pm 258.02$ & $315.87 \pm 208.90$ \\
n-6 & $394.72 \pm 63.66$ & $377.57 \pm 132.98$ & $1462.11 \pm 443.06$ & $533.73 \pm 30.62$ \\
EPA & $31.62 \pm 14.55$ & $273.83 \pm 115.00$ & $243.51 \pm 54.60$ & $55.56 \pm 44.93$ \\
DHA & $30.99 \pm 8.72$ & $214.84 \pm 89.93$ & $375.55 \pm 73.18$ & $94.95 \pm 57.31$ \\
\hline
\end{tabular}

that in Siberian sturgeon and wels catfish (3.7\% and 3.01\%), lower in bighead carp (2.29\%), and the lowest in grass carp $(1.08 \%)$. In other freshwater fish species, EPA content varied from $0.65 \%$ up to $20.15 \%$, whereas DHA level varied from $0.72 \%$ up to $27.08 \%[17,33,34]$. The EPA and DHA values determined in the present research for grass carp, bighead carp, Siberian sturgeon, and wels catfish fall within these ranges. The percentage share of fatty acids in the fat does not reflect the concentration of these acids expressed as $\mathrm{mg} / 100 \mathrm{~g}$ in muscle tissue. The fatty acids expressed in $\mathrm{mg} / 100 \mathrm{~g}$ fish muscle tissue allow for determination of nutritive and a properly balanced diet. For wider information, the contents of SFA, MUFA, PUFA, and n-3 and n- 6 family as well as EPA and DHA in the muscle tissue of the analyzed fish are presented in Table 2. In the fish species analyzed, EPA content was between 31.62 and 273.83, while DHA content was from 30.99 up to $375.55 \mathrm{mg} / 100 \mathrm{~g}$ muscle tissue. The least amount of these acids (including $\mathrm{EPA}+\mathrm{DHA} \mathrm{mg} / \mathrm{l00} \mathrm{g}$ ) was found in the grass carp muscle tissues (62.61), with higher concentrations found in the muscle tissues of wels catfish (150.51) and markedly higher ones in the muscle tissue of bighead carp (488.67) and Siberian sturgeon (619.06). The level of EPA + DHA mg/100 g also varied among other farmed fish species and reached 24.8 in sutchi catfish, 70.8 in tilapia, 214.5 in carp, and 1804.0 in trout [3]. The majority of recommendations have been issued on the basis of the amount of EPA + DHA together, without specific guidance for each fatty acid [12]. The European Food Safety Authority recommends the intake of $250 \mathrm{mg} /$ day EPA + DHA [35]. The results obtained in this study indicated that the recommended dose $250 \mathrm{mg} /$ day of EPA + DHA was available in about $40 \mathrm{~g}$ of sturgeon, $50 \mathrm{~g}$ of bighead carp, $170 \mathrm{~g}$ of wels catfish, and $400 \mathrm{~g}$ of grass carp. Arachidonic acid (AA) (C20:4 n-6) concentration was the highest in grass carp $(2.72 \%)$ followed by bighead carp (1.34\%), whereas it was the lowest and comparable in Siberian sturgeon and wels catfish (0.48 and $0.4 \%$, resp.). Ljubojević et al. [28] indicated a lower arachidonic acid content in grass carp (1.61\%) and a higher one in bighead carp and wels catfish (4.05\% and 3.55\%, resp.) compared to the levels established in these species in the present studies. According to Badiani et al. [29], arachidonic acid concentration in cultured sturgeon oscillated between $0.44 \%$ and $1.16 \%$ and the values determined for this fish species in the current research were found within this range. A content of arachidonic acid in other farmed fish species such as trout, sutchi catfish, carp, and tilapia varied between $0.5 \%$ and $1.9 \%$ [3], while for carp, bream, pike, and zander it varied between $2.52 \%$ and $4.57 \%$ [22]. The $1.4: 1-2: 1$ proportion of DHA (docosahexaenoic acid) to AA (arachidonic acid) proves beneficial for pregnant women [12] and this proportion was determined in the bighead carp fat $(2.29: 1.34)$. As for grass carp, Siberian sturgeon, and wels catfish, these acids were found at a different ratio, that is, $1.08: 2.72,3.7: 0.48$, and $3.01: 0.4$, respectively.

The analysis of fatty acid profile of the fat of grass carp, bighead carp, Siberian sturgeon, and wels catfish analyzed in the present studies as well as the research results presented by other authors showed the differences in concentration of fatty acids. The effect of species, age, diet, water salinity, season, and geographical location on the fatty acid profile of fish fat is well evidenced by other authors [1, 16, 36-39] and that explains the differences in fatty acid profiles of fish fat.

\section{Conclusion}

Fatty acid profile of the fat of the examined fish depended on the fish species. The fish species analyzed in the present research make a source of essential unsaturated fatty acids. The ratios of n- 6 to $n-3$ fatty acids and polyunsaturated fatty acids to saturated fatty acids (PUFA/SFA) in the fat of the fish examined proved to be advantageous. The results have shown that the investigated fish species may constitute a healthy addition to the human diet.

\section{Additional Points}

Practical Applications. This study has documented effect of fish species on the fatty acid profile and nutritive value of fat of the muscle tissue of four species of important food fish. The obtained research results could serve as reference to nutritionists or dieticians.

\section{Disclosure}

This article does not contain any studies with human participants or animals performed by any of the authors.

\section{Conflicts of Interest}

The authors declare that they have no conflicts of interest. 


\section{References}

[1] M. Ćirković, D. Trbović, D. Ljubojević, and V. Đordević, "Meat quality of fish farmed in polyculture in carp ponds in Republic of Serbia," Tehnologija Mesa, vol. 52, no. 1, pp. 106-121, 2011.

[2] F. Jabeen and A. S. Chaudhry, "Chemical compositions and fatty acid profiles of three freshwater fish species," Food Chemistry, vol. 125, no. 3, pp. 991-996, 2011.

[3] Z. Usydus, J. Szlinder-Richert, M. Adamczyk, and U. Szatkowska, "Marine and farmed fish in the Polish market: Comparison of the nutritional value," Food Chemistry, vol. 126, no. 1, pp. 78-84, 2011.

[4] D. Sarma, M. S. Akhtar, P. Das et al., "Nutritional quality in terms of amino acid and fatty acid of five coldwater fish species: implications to human health," National Academy of Science Letters, vol. 36, no. 4, pp. 385-391, 2013.

[5] P. S. Shi, Q. Wang, Y. T. Zhu, Q. H. Gu, and B. X. Xiong, "Comparative study on muscle nutritional composition of juvenile bighead carp (Aristichthys nobilis) and paddlefish (Polyodon spathula) fed live feed," Turkish Journal of Zoology, vol. 37, no. 3, pp. 321-328, 2013.

[6] Y. Kaya, M. E. Erdem, and H. Turan, "Monthly differentiation in meat yield, Chemical and amino acid composition of wild and cultured brown trout (Salmo trutta forma fario Linneaus, 1758)," Turkish Journal of Fisheries and Aquatic Sciences, vol. 14, no. 2, pp. 479-486, 2014.

[7] Y. Wang, S. Yu, G. Ma, S. Chen, Y. Shi, and Y. Yang, "Comparative study of proximate composition and amino acid in farmed and wild Pseudobagrus ussuriensis muscles," International Journal of Food Science and Technology, vol. 49, no. 4, pp. 983-989, 2014.

[8] L. Polak-Juszczak and K. Komar-Szymczak, "Fatty acid profiles and fat contents of commercially important fish from Vistula Lagoon," Polish Journal of Food and Nutrition Sciences, vol. 59, no. 3, pp. 225-229, 2009.

[9] A. P. Simopoulos, "Omega-3 fatty acids in health and disease and in growth and development," The American Journal of Clinical Nutrition, vol. 54, no. 3, pp. 438-463, 1991.

[10] B. J. Hunter and D. C. K. Roberts, "Potential impact of the fat composition of farmed fish on human health," Nutrition Research, vol. 20, no. 7, pp. 1047-1058, 2000.

[11] P. M. Kris-Etherton, W. S. Harris, and L. J. Appel, "Fish consumption, fish oil, omega-3 fatty acids, and cardiovascular disease," Circulation, vol. 106, no. 21, pp. 2747-2757, 2002.

[12] P. M. Kris-Etherton, J. A. Grieger, and T. D. Etherton, "Dietary reference intakes for DHA and EPA," Prostaglandins, Leukotrienes and Essential Fatty Acids, vol. 81, no. 2-3, pp. 99104, 2009.

[13] A. P. Simopoulos, "Omega-3 fatty acids in inflammation and autoimmune diseases," Journal of the American College of Nutrition, vol. 21, no. 6, pp. 495-505, 2002.

[14] J. Mayneris-Perxachs, I. Bondia-Pons, L. Serra-Majem, A. I. Castellote, and M. C. López-Sabater, "Long-chain n-3 fatty acids and classical cardiovascular disease risk factors among the Catalan population," Food Chemistry, vol. 119, no. 1, pp. 54-61, 2010.

[15] H. D. Le, J. A. Meisel, V. E. de Meijer, K. M. Gura, and M. Puder, "The essentiality of arachidonic acid and docosahexaenoic acid," Prostaglandins, Leukotrienes and Essential Fatty Acids, vol. 81, no. 2-3, pp. 165-170, 2009.

[16] M. Çelik, A. Diler, and A. Küçükgülmez, "A comparison of the proximate compositions and fatty acid profiles of zander
(Sander lucioperca) from two different regions and climatic conditions," Food Chemistry, vol. 92, no. 4, pp. 637-641, 2005.

[17] Y. Özogul, F. Özogul, and S. Alagöz, "Fatty acid profiles and fat contents of commercially important seawater and freshwater fish species of Turkey: a comparative study," Food Chemistry, vol. 103, no. 1, pp. 217-223, 2007.

[18] G. Li, A. J. Sinclair, and D. Li, "Comparison of lipid content and fatty acid composition in the edible meat of wild and cultured freshwater and marine fish and shrimps from China," Journal of Agricultural and Food Chemistry, vol. 59, no. 5, pp. 1871-1881, 2011.

[19] M. R. Ghomi, M. Nikoo, and Z. Babaei, "Fatty acid composition in farmed great sturgeon Huso huso," Comparative Clinical Pathology, vol. 21, no. 1, pp. 111-114, 2012.

[20] E. Prato and F. Biandolino, "Total lipid content and fatty acid composition of commercially important fish species from the Mediterranean, Mar Grande Sea," Food Chemistry, vol. 131, no. 4, pp. 1233-1239, 2012.

[21] P. Nieminen, E. Westenius, T. Halonen, and A.-M. Mustonen, "Fatty acid composition in tissues of the farmed Siberian sturgeon (Acipenser baerii)," Food Chemistry, vol. 159, pp. 8084, 2014.

[22] E. R. Grela, R. K. Pisarski, E. Kowalczuk-Vasilev, and A. Rudnicka, "Content of nutrients and minerals, and fatty acid profile in some fish flesh depending on fishing period," Żywność. Nauka. Technologia. Jakość, vol. 71, no. 4, pp. 63-72, 2010.

[23] PN-A-86734, "Fish, their derived products and by-products. Determination of fat content," 1967.

[24] ISO, 12966-1 "Animal and vegetable fats and oils-Gas chromatography of fatty acid methyl esters-Part 1: Guidelines on modern gas chromatography of fatty acid methyl esters," 2014.

[25] ISO, 12966-2 "Animal and vegetable fats and oils-Gas chromatography of fatty acid methyl esters-Part 2: Preparation of methyl esters of fatty acids," 2011.

[26] J. Exler, J. E. Kinsella, and B. K. Watt, "Lipids and fatty acids of important finfish: new data for nutrient tables," Journal of the American Oil Chemists' Society, vol. 52, no. 5, pp. 154-159, 1975.

[27] PN-A-86770, "Fish and fishery products - Terminology," 1999.

[28] D. Ljubojević, M. Ćirković, V. Dordević et al., "Fat quality of marketable fresh water fish species in the Republic of Serbia," Czech Journal of Food Sciences, vol. 31, no. 5, pp. 445-450, 2013.

[29] A. Badiani, P. Anfossi, L. Fiorentini et al., "Nutritional composition of cultured sturgeon (Acipenser spp.)," Journal of Food Composition and Analysis, vol. 9, no. 2, pp. 171-190, 1996.

[30] J. Łuczyńska, B. Paszczyk, and M. J. Łuczyński, "Fatty acid profiles in marine and freshwater fish from fish markets in northeastern Poland," Archives of Polish Fisheries, vol. 22, no. 3, pp. 181-188, 2014.

[31] A. B. Moreira, J. V. Visentainer, N. E. de Souza, and M. Matsushita, "Fatty acids profile and cholesterol contents of three Brazilian Brycon freshwater fishes," Journal of Food Composition and Analysis, vol. 14, no. 6, pp. 565-574, 2001.

[32] HMSO, "Nutritional aspects of cardiovascular disease (report on health and social subjects No. 46) London," 1994.

[33] E. İ. Cengiz, E. Ünlü, and M. Başhan, "Fatty acid composition of total lipids in muscle tissues of nine freshwater fish from the River Tigris (Turkey)," Turkish Journal of Biology, vol. 34, no. 4, pp. 433-438, 2010.

[34] J. Łuczyńska, Z. Borejszo, and M. Łuczyński, “The composition of fatty acids in muscles of six freshwater fish species from the Mazurian Great Lakes (Northeastern Poland)," Archives of Polish Fisheries, vol. 16, no. 2, pp. 167-178, 2008. 
[35] EFSA, "Scientific opinion of the panel on dietetic products, nutrition and allergies on a request from the European Commission related to labelling reference intake values for $n-3$ and n-6 polyunsaturated fatty acids," EFSA Journal, vol. 1176, pp. 111, 2009.

[36] S. A. Rahman, T. S. Huah, O. Nassan, and N. M. Daud, "Fatty acid composition of some Malaysian freshwater fish," Food Chemistry, vol. 54, no. 1, pp. 45-49, 1995.

[37] W. Steffens and M. Wirth, "Freshwater fish-an important source of n-3 polyunsaturated fatty acids: a review," Archives of Polish Fisheries, vol. 13, no. 1, pp. 5-16, 2005.

[38] H. I. Haliloğlu, A. Bayir, A. N. Sirkecioğlu, N. M. Aras, and M. Atamanalp, "Comparison of fatty acid composition in some tissues of rainbow trout (Oncorhynchus mykiss) living in seawater and freshwater," Food Chemistry, vol. 86, no. 1, pp. 5559, 2004.

[39] E. I. Cengiz, E. Ünlü, M. Bashan, A. Satar, and E. Uysal, "Effects of seasonal variations on the fatty acid composition of total lipid, phospholipid and triacylglicerol in the dorsal muscle of mesopotamian catfish (Silurus triostegus Heckel, 1843) in Tigris River (Turkey)," Turkish Journal of Fisheries and Aquatic Sciences, vol. 12, no. 1, pp. 33-39, 2012. 

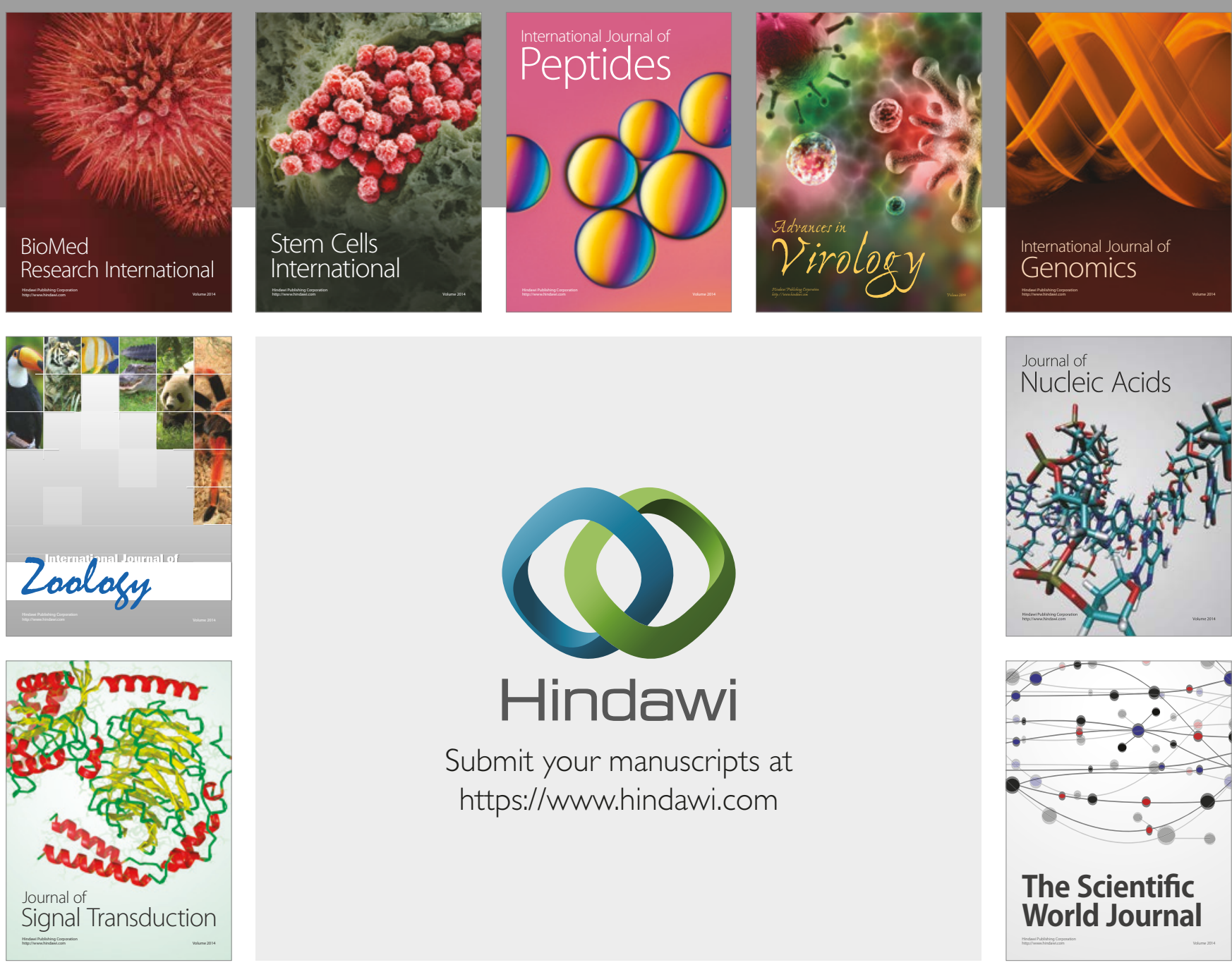

Submit your manuscripts at

https://www.hindawi.com
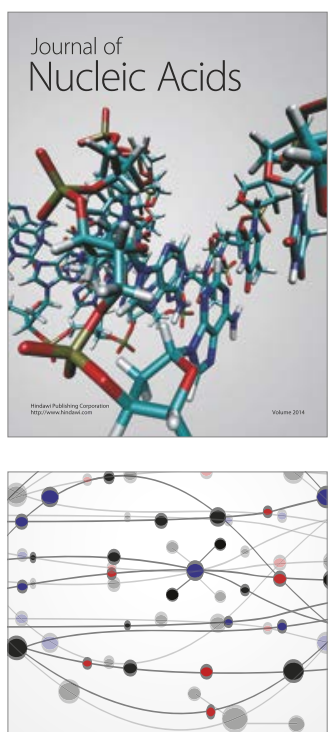

The Scientific World Journal

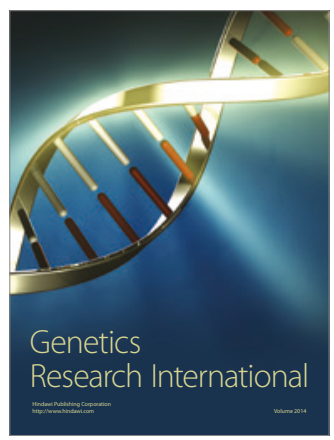

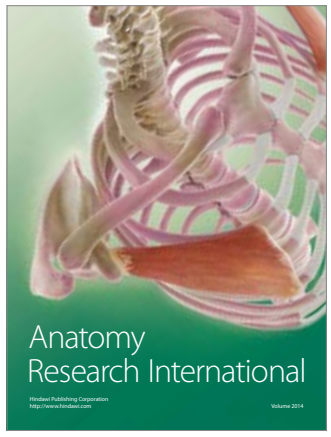

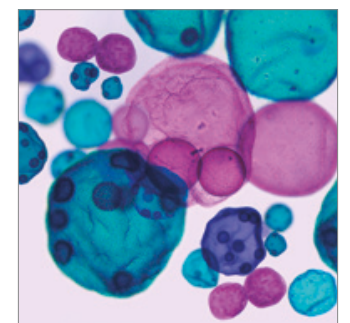

International Journal of Microbiology
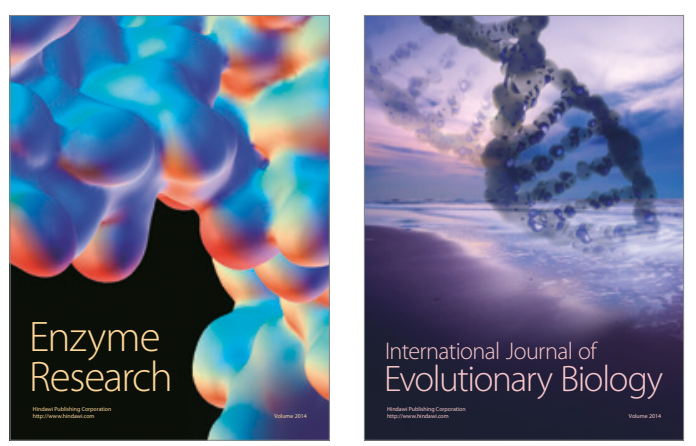
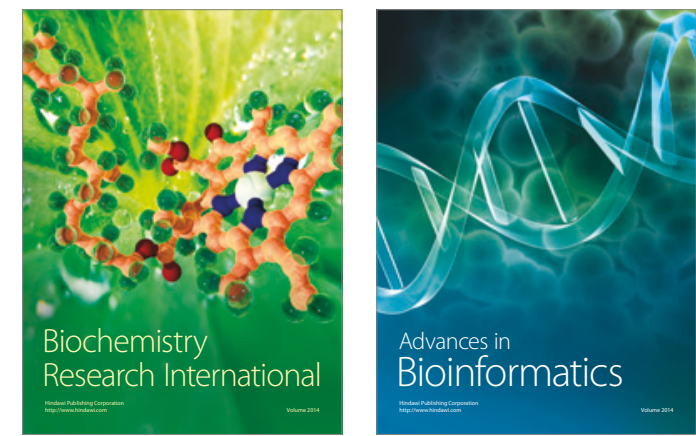

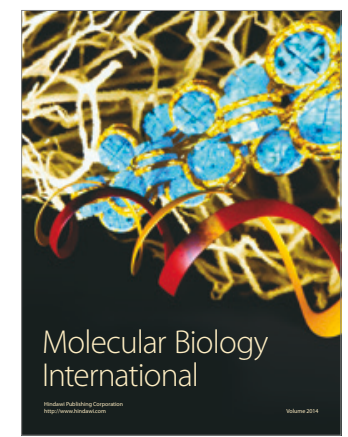

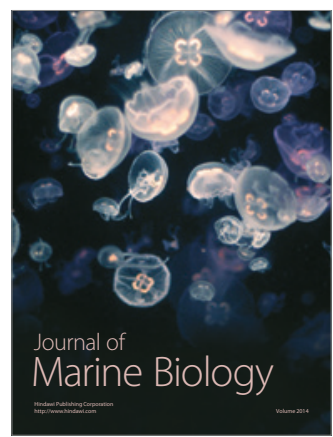

